\title{
Experiments on the Behavior of Telephone Cables in Fires
}

\author{
OSAMI SUGAWA and TAKASHI HANDA
}

Center for Fire Science and Technology

Science University of Tokyo

2641 Yamasaki, Noda-shi, Chiba 278, Japan

\section{ABSTRACT}

Full scale experiments have been conducted with telephone cables in an attempt to simulate the thermal and atmospheric conditions of a real cable fire. The cables used for the experiments had polyethylene sheathing and were of the same specification and layout as those in the real fire. Temperature, gas concentration, smoke concentration, and hot air velocity were measured and recorded every 15 sec. Thousand pairs of wires were monitored to record the times of their communication stoppages due to fire. Temperatures around the ignition region showed $800^{\circ} \mathrm{C}$ after $5 \mathrm{~min}$, and the average flame spread over the surface of the cables was about $3 \mathrm{~m} / \mathrm{min}$ along the tunnel. It was found that the stoppage against time showed a normal distribution with a standard deviation of 2 - $3 \mathrm{~min}$. Based on the comparison of both stoppage behaviors of the experiments and the real fire, the start time and the propagation of the real fire were estimated.

KEY WORDS: cable fire, telephone cable, polyethylene sheathing, stoppage of communication, normal distribution, cable tunnel

\section{INTRODUCTION}

A Pire occurred in the Setagaya Telephone Cable Tumel, Tokyo at around 11:30 a.m. on 16 November 1985.[1] The fire was extinguished by the next morning after 17 hours of fire fighting with water. About $200 \mathrm{~m}$ length of 104 cables in the tunnel were burnt out. About 89,000 installed subscribers, 1,400 public telephones, and 2,800 data communication services were eut off from the Setagaya telephone network for 7 - 10 days. The data communication systems used for banks and security companies through the Setagaya Telephone Cables automatically recorded the times with hour, minutes and seconds when each communication functioning ceased. The sequence of stoppage times of all these communication wires with regarding of which locations implied the direction of the fire propagation in the tunnel.

Many cable fire tests were carried out to evaluate the burning behavior of (vertically supported) cables [2 - 6] according to the specification of IEEE standard 383. The behavior of a cable fire (including a group cable fire) is not well determined when it occurs in a tunnel. The cable burns under strong radiation and limited air supply in a tunnel [7,8], but there is little information available on the burning behavior under such conditions. The objective of this paper is to examine the burning behavior of cables in a tunnel fire test under 
the same layout which existed in the Setagaya fire. We paid special attention to obtaining the sequence of stoppage occurrence as well as the basic information necessary to assess the speed of fire development and temperature distribution in the early stages of the fire. The results of the tests may help to determine fire prevention measures as well as calculating risk analysis.

\section{EXPERIMENTAI PROCEDURES}

Based on the witness and workers reports, cable layout and size of the Setagaya tunnel, and the sequence of the stoppage times of the communication functioning, the following fire test procedures were adopted. The cross section of the experimental tunnel, which was made of a reinforced concrete, is shown in Figure 1. The tunnel was set on a horizontal concrete slab in an open field. About 2/3 of the upper area of one open-end was covered with a thick plaster board to reduce the effects natural wind. The other was fully opened to exhaust the smoke of the fire. The vertical steel hungers were attached to both inside walls every $0.8 \mathrm{~m}$. The circles on the racks, in Figure 1, indicate the cables, some of which were bundled on racks with cotton cords as they would be in the real cable tunnel. We adopted X-axis along the tunnel with $X=0$ at the center. The layout and number of cables are significant factors as fuel mass distribution. The cable layout in the experiment was chosen carefully so as to be the same as same as the layout in the Setagaya telephone cable tunnel. Therefore, 42

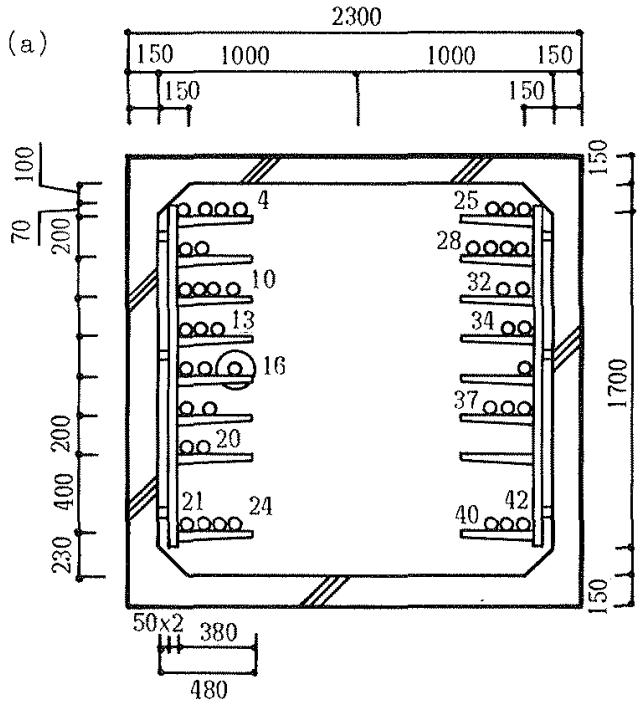

\section{Figure 1}

Schematic drawing of the cross section of the model tunnel with 42 numbered cables.

(a) cross section at $\mathrm{X}=\mathrm{Om}$,

(b) cross section along the tunnel.

(b)

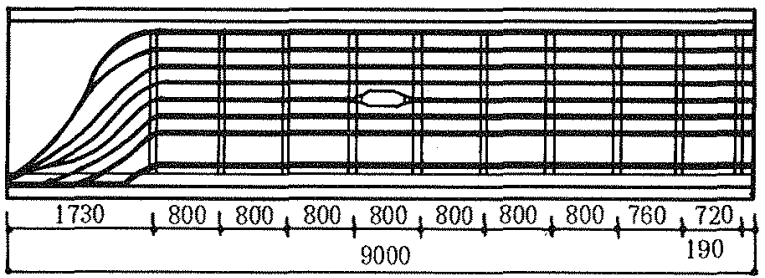


telephone cables, 24 cables for one side and 18 cables for the other side, were used in the experiments. No power cable was included. The wires were covered with thin aluminum tapes and wavy folded steel plates. and polyethylene sheathing. The cables had an outer diameter of about $70 \mathrm{~mm}$, with about $3 \mathrm{~mm}$ thick polyethylene sheathing. One cable, indicated with a large circle in Figure 1, had a connection service cylindrical box covered made of thick lead. This metal cover was opened by two workers using gasoline torches prior to ignition of the system. A $5 \mathrm{~kg}$ cotton sheet, without fire retarding, was set on the cables \#17 and \#18 which vere located just under cable \#16. The one end of the sheet touched and spread out about $0.2-0.3 \mathrm{~m}$ on the tunnel floor. After opening the lead cover, a gasoline torch with a very small flame was put on the sheet and this flame touched the sheet and ignited it. Ignition was carried out at the center, $\mathrm{X}=0$, of the tunnel. The ignition material and method adopted in the experiment were similar to the fire scenario of the Setagaya Cable Fire.

The stoppage in transmission over the telephone wires due to fire was monitored and recorded for 1,000 pairs of wires chosen from the 42 cables. Temperatures in the tunnel were measured at 108 points by means of thermocouples ( $K$-type) at $X=-0.5,0,0.5,1.0$ and $3.0 \mathrm{~m}$, respectively. Concentrations of $\mathrm{CO}_{2}, \mathrm{CO}$ and $\mathrm{O}_{2}$ gases, smoke concentration, and velocity were also measured. Outputs from thermocouples, gas analyzers, pressure gauge etc., were recorded every 15 seconds.

\section{RESULTS AND DISCUSSION}

The experiments were carried out twice using the same specifications for the cables and cotton sheet, and the same model turnel. The burning zone on the sheet spread forming a triangular shape and a flame reached the connection parts of cable \#16 after $60-103$ sec following ignition. Flames propagated to the upper cables \#13, \#9 and \#10. Drippings of flaming polyethylene from the burning sheathing dropped on cable \#17 - \#24 and started many new areas of fire. Flame spread along the ceiling and reached the opposite side. Cables \#25 \#27, were the first to ignite on the opposite side. Many flaming arippings from these cables dropped onto the lower cables and, again, new areas of fire. The visual observation of the fire are shown in Table 1. The flame length of the torch in experiment \#1 was slightly longer than that in \#2. This gave slightly faster propagation time, as shown in Table 1 .

Table 1 Elapsed time from burning of the sheet

\begin{tabular}{lll}
\hline items & Exp. \#1 & Exp. \#2 \\
\hline Touch flame to sheet & $0 \mathrm{~min} 00 \mathrm{sec} 0 \mathrm{~min} 00 \mathrm{sec}$ \\
Flame height about 20cm & $0 \mathrm{~min} 30 \mathrm{sec} 1 \mathrm{~min} 16 \mathrm{sec}$ \\
Reach to cable \#16 & $1 \mathrm{~min} 00 \mathrm{sec} 1 \mathrm{~min} 43 \mathrm{sec}$ \\
Flame height about 100cm & $1 \mathrm{~min} 20 \mathrm{sec} 2 \mathrm{~min} 11 \mathrm{sec}$ \\
Flame reached to ceiling & $3 \mathrm{~min} 08 \mathrm{sec} 4 \mathrm{~min} 59 \mathrm{sec}$ \\
Flame length about $1.5 \mathrm{~m}$ & $3 \mathrm{~min} 26 \mathrm{sec} 5 \mathrm{~min} 30 \mathrm{sec}$ \\
under ceiling & Flame reached to opposite \\
side and start of burning & $3 \mathrm{~min} 30 \mathrm{sec} 5 \mathrm{~min} 35 \mathrm{sec}$ \\
torch burst out & $6 \mathrm{~min} 07 \mathrm{sec} 8 \mathrm{~min} 30 \mathrm{sec}$ \\
\hline
\end{tabular}


It is clear to see how the burning area spread from the temperature distribution diagrams. Figure 2-a shows the temperatures at $X=0$ after 5 min in experiment \#2. The flame from the left side cables began to spread to the opposite side. After $6 \mathrm{~min}$, flame propagated to the cables on the top rack of the right side. Figures $2-\mathrm{b}$ and $2-\mathrm{c}$ show temperatures at $7 \mathrm{~min}$ at $X=0$ and along the tumel, respectively. After $8 \mathrm{~min}$, the temperature rise ranged from 700 to over $900^{\circ} \mathrm{C}$, and the burning of the cables was fully developed. As is illustrated in Figure 2-c, it is likely that at that time, a hot layer of over $600^{\circ} \mathrm{C}$ approximately, with thick black smoke, formed to about a $15-20 \mathrm{~cm}$ thickness. The evaluation of recorded temperatures, along cables \#2 and \#3, shows that representative average spread rate of burning front for horizontal direction was about $3 \mathrm{~m} / \mathrm{min}$ during the first 7 min. This value is extremely large compared to Suzuki et al. $[9,10]$. They reported a horizontal flame spread velocity of about $0.1 \mathrm{~m} / \mathrm{min}$ under the ventilated condition of about $3 \mathrm{~m} / \mathrm{sec}$ using polyethylene sheathing cable placed horizontally in a small-scale duct model. This may be not only due to the intensive radiative heat flux. $[9,11]$ from burning zone but also due to the convective heat flux in the hot smoky flow. In the first $7 \mathrm{~min}$, the observed air velocity under the ceiling was $2-3 \mathrm{~m} / \mathrm{sec}$. The average downward flame spread rate in the vertical direction in the early stage of the fire, which was mainly due to the burning drippings of polyethylene, was about $1 \mathrm{~m} / \mathrm{min}$. This shows that the burning behavior of cables strongly depends on the scale factor, configuration, and

(a)

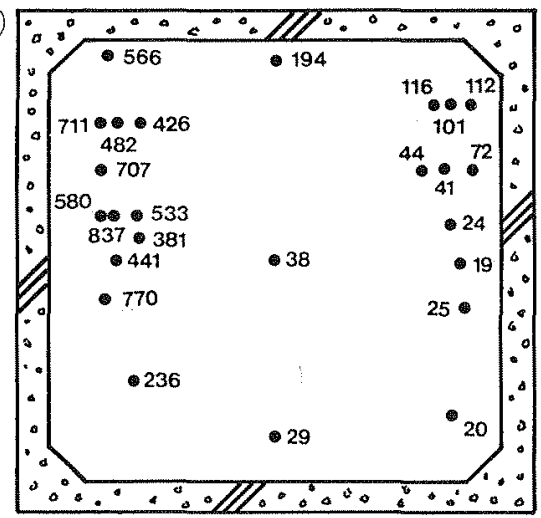

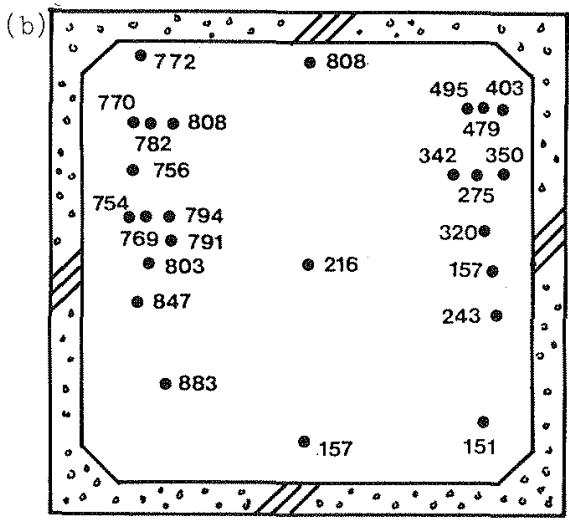

(c)

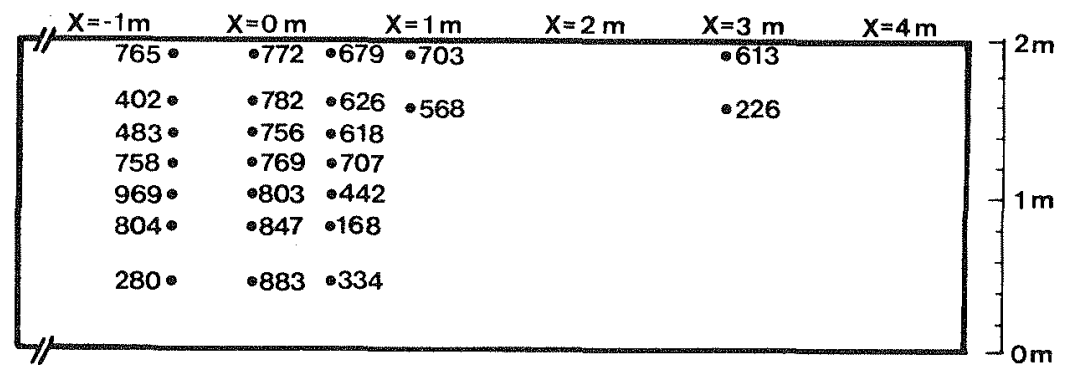

Figure 2 Temperatures in the cross section at the center of the tunnel, (a) 5 min after, (b) and (c) 7 min after the initiation of fire. 
materials of the tunnel/duct.

When the sheet had been burnt and began to ignite the wires of cable \#16, $\mathrm{CO}$ gas concentration had been about $2 \%$ and $\mathrm{CO}$ gas about 0.5 - $0.8 \%$. After $5 \mathrm{~min}$, flames from the first cables, reached to the ceiling and both $\mathrm{CO}$ and $\mathrm{CO}$ concentrations increased to $3.4 \%$ and 13 $16 \%$, respectively. It is likely that the co concentration increased with time, but $\mathrm{CO}_{2}$ gas concentration stayed roughly constant. The oxygen concentration decreased abruptly to about $1 \%$ after 5 min corresponding with the stage of fully burning cables. Optical smoke concentration indicated $\mathrm{CS}_{\mathrm{S}}=0.1-4(1 / \mathrm{m})$ when the sheet had been burning and then increased abruptly over scale as cables burned and gave off thick smoke. The air velocity at $X=3 \mathrm{~m}$ and $10 \mathrm{~cm}$ below the ceiling increased from about $1 \mathrm{~m} / \mathrm{sec}$ to $3.5 \mathrm{~m} / \mathrm{sec}$ when cables began to burn intensely.

An evaluation of the recorded time order of stoppages in the cables showed that stoppage occurred first in the outer units of the wire groups and then spread into the inner units. Each stoppage appeared discretely when plotted against elapsed time. In order to estimate the stoppage behavior in all units of a cable, the number of stoppages were accumulated with time and also plotted against time. Figure 3 shows the relation between cumulative counts of stoppages and time, as obtained from cable \#9. From the behavior of 42 cables, the occurrence of stoppages in a cable appeared to be a normal distribution with time. Therefore, stoppage behavior was simulated based on the norma. distribution, as illustrated in Figure 3. The cumulative curves were simulated based on the normal distribution and good agreement with the data was obtained. The normal distribution obtained in the appearance of stoppages may be explained in terms of the central limited theory. It is supposed that as wire sheathing melts at various local points inside the cable, the underlying wires in the cable are almost equally and simultaneously exposed to the surrounding high temperatures and immediately fail, because wires in the cable are packed tightly. It is likely that a stoppage represents the partial stoppage. Table 2 shows the mean times and standard deviations of stoppage time of each cable. The times in Tables 2 are the mean times of stoppage using the stoppage of cable \#16 as time zero. In experiments \#1, the modified exchange machine failed, and some stoppage times could not be obtained. We excluded the data from the statistics for the cables which had small number of wires connected to the modified exchange machine. The development of fire in the tunnel could be divided roughly into three regions. The burning region located above cable \#16, where burning started with cables on the 4 th rack (cable \#13) and proceeded towards the top rack (cables $\# 1$ - \#4). Then, the flames from the burning cables, such as \#1 - \#16, reached to cables \#25 - \#27 and caught fire. At that time drippings of flaming polyethylene initiated another burning region below cable \#16 as the third region. Table 3 shows the mean times of initiation of burning of the lower cables. The start of the burning of cables \#1 - \#4 on the top rack almost coincided with the burning initiation times of \#25 - \#40.

of about 1,200 records of stoppage sequence obtained in the Setagaya fire, 651 records, which were included in the three independent cables A, B and $C$ were selected. These cables corresponded to cables \#9, \#10, and \#34 respectively in the experiment. As shown in Figure 3 , the stoppage behavior of wires in a cable showed normal distribution. Therefore, we plotted the accumulated counts of stoppages against time as shown in Figure 4. Table 4 shows the mean and standard deviation of 
stoppage times obtained from these three cables. The telephone cable had 18 units of wire groups (200 pairs of wires per unit) which consisted of a core of one unit at the center, 7 units (\#2 - \#8) for the second layer, and 11 units (\#9-\#18) for the third layer. The wires of the stoppages recorded within cables $A$ and $B$ belonged to unit \#20 - \#24 in the third layer, and to \#3 - \#10 of the second layer, respectively. Cables $A$ and $B$ located on the same rack were nearest to each other. The cable layouts and observations of the fire propagation in the experiments showed that these two cables began to burn at almost the same time and they were the first cables which caught fire from cable \#16. The stoppage behavior of cables A and B could therefore be treated as a single cable stoppage.

Table 2. Mean time and Standard deviation of Stoppage

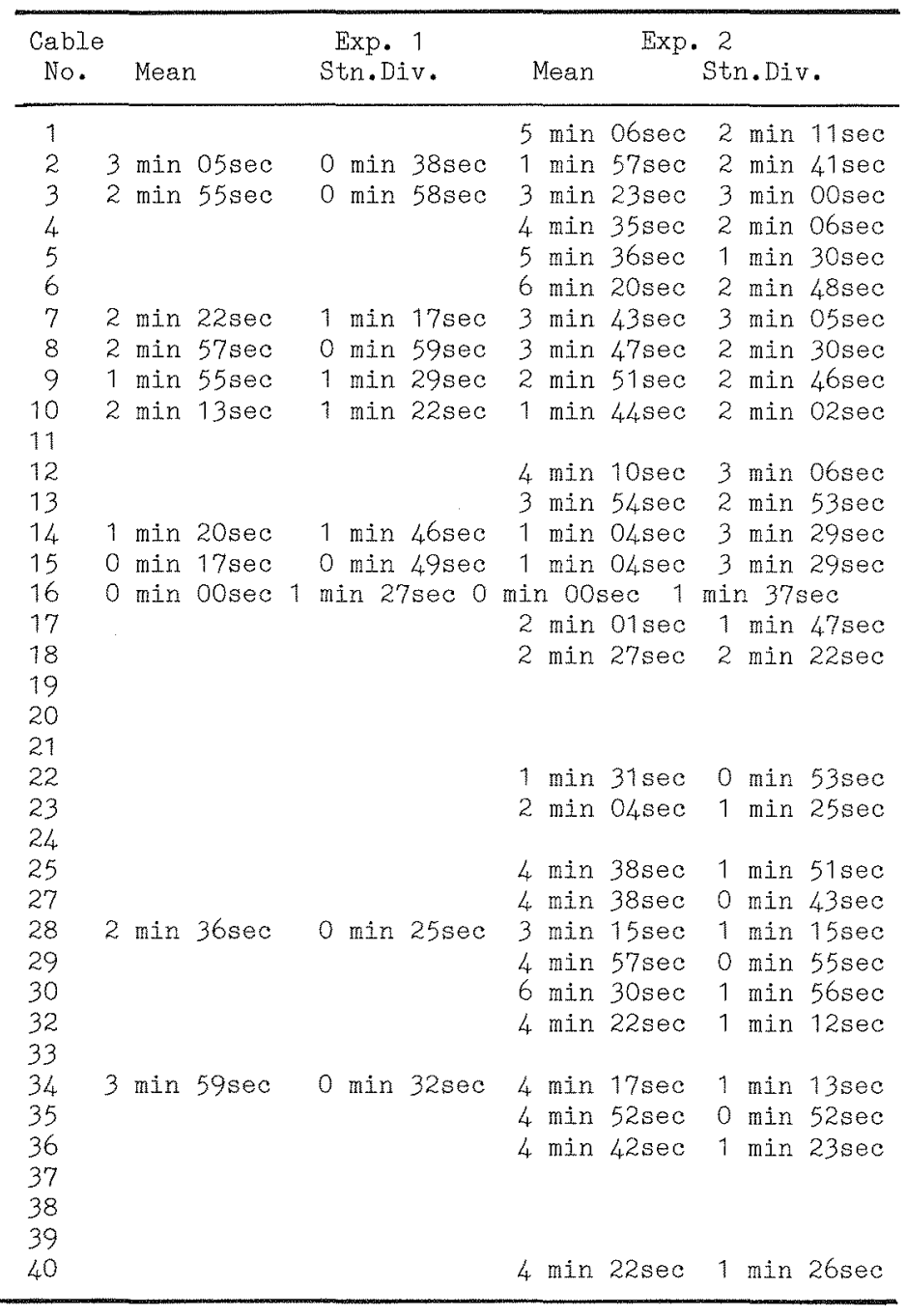


The mean time and standard deviation of stoppages of communication function for cables $A$ and $B$ are added in Table 3. Fire spread from cable $\mathrm{A}+\mathrm{B}$ to cable $\mathrm{C}$ taking $7 \mathrm{~min} 50 \mathrm{sec}-11 \mathrm{~min} 46 \mathrm{sec}$ at the $95 \%$ confidence range.

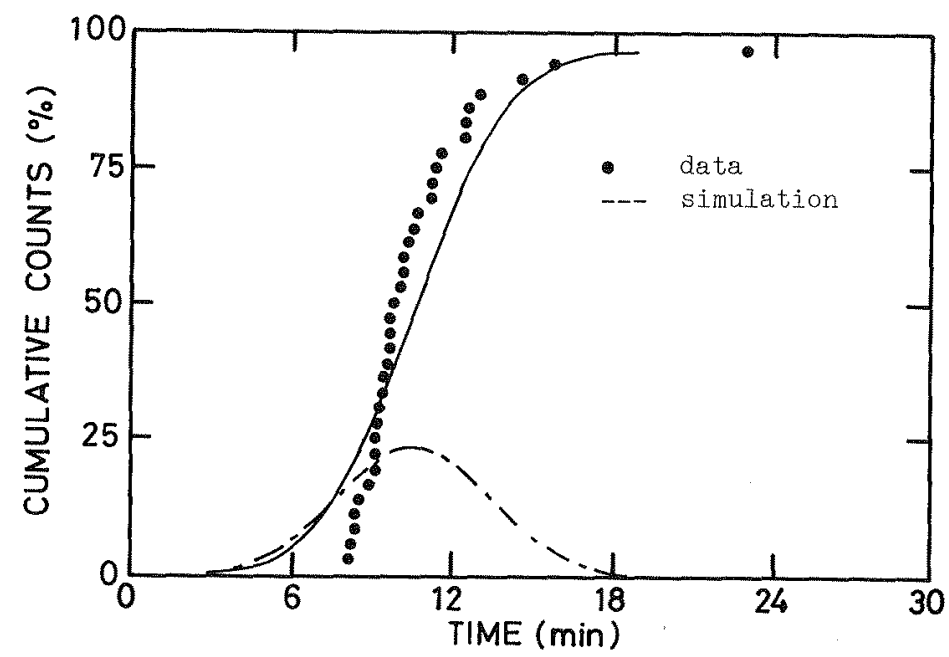

Figure 3 Cumulative counts of stoppage in cable \#9 against elapsed time obtained in the experiment \#2.

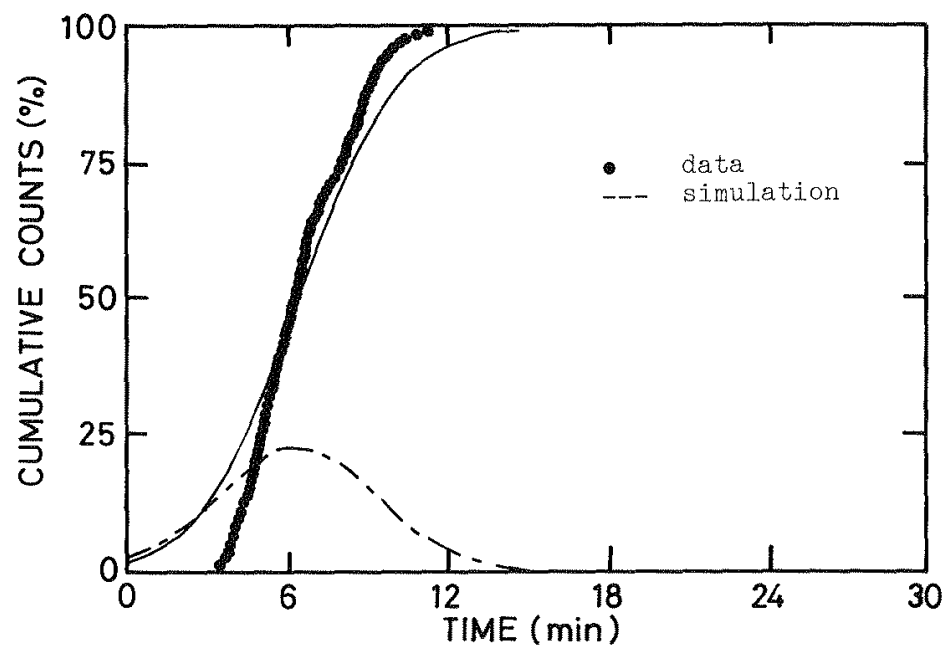

Figure 4 Cumulative counts of stoppage in cable A against elapsed time obtained in Setagaya Cable Fire.

The stoppage behavior of cables both in the experiments and in the Setagaya fire showed a similar pattern of normal distribution, as shown in Figures 3 and 4. The walls of the model tunnel were dry and well ventilated from the outside. In the Setagaya cable tunnel, on the contrary, the walls were very wet from ground water and had a poor air 
supply as compared to the model. These differences in the turnel condition gave slow fire propagation speed in the Setagaya tunnel. The model of the time difference between the experiment and real fire is illustrated in Figure 5. The suppression rate, the ratio of $t / t_{0}$, was estimated by comparing the fire growth rate between cable \#9 $\$$ \#10 to \#34 in the experiment, and cable A $+B$ to cable $C$ in the setagaya fire. In experiment \#1, the flame was a little longer than the one in the second experiment. Therefore, we uses the results of experiment \#2 for making a comparison with the real fire. The evaluation of times in Table 5 shows that the suppression rate may be $0.25-0.3$ compared to the experiment 2. Table 4 and Table 5 could give an estimated mean time of stoppage of cable \#16 in the real fire of about 7 min 50 sec -11 min 46 sec before the mean time stoppages in cables \#9+\#10. Hence, it could be said that the mean time stoppage of the cable which corresponds to cable \#16 in the test fire located between 11:38:32 - 11:42:24 a.m.. Table 2 shows the standard deviation of stoppage in cable \#16 to be 87 and 97 seconds for experiments \#1 and \#2, respectively. We adopted 92 seconds of the averaged previous times as the standard deviation. Taking the standard deviation of 92 seconds and a suppression rate of 0.25 0.3 for the cable, corresponding to cable \#16, it could be estimated that the first cable stoppage in the real fire may be between 11:26:43 $11: 33: 13$ a.m.

Table 3 Average of mean times [min:sec]

\begin{tabular}{llll}
\hline Cable & Exp. 1 & Exp. & \multicolumn{1}{c}{ Note } \\
\hline cable \#16 & $0: 00$ & $0: 00$ & adopted as start \\
cable \#9 - \#10 & $2: 04$ & $2: 18$ & 2 racks over \#16 \\
cable \#1-\#4 & $3: 00$ & $4: 21$ & 4 racks over \#16 \\
cable \#25-\#40 & $3: 29$ & $4: 49$ & opposite side \\
cable \#17-\#24 & ---- & $2: 00$ & below \#16 \\
\hline
\end{tabular}

Table 4 Mean time and Standard deviation of Stoppage time Obtained in Setagaya Fire

\begin{tabular}{ccc}
$\begin{array}{c}\text { Corresponding } \\
\text { Cable Number }\end{array}$ & $\begin{array}{c}\text { Mean time } \\
{[\mathrm{h}: \mathrm{m}: \mathrm{s}]}\end{array}$ & $\begin{array}{c}\text { Stn. Div. } \\
{[\text { sec] }}\end{array}$ \\
\hline $\mathrm{A}(9)$ & $11: 48: 30$ & 121.5 \\
$\mathrm{~B}(10)$ & $11: 46: 57$ & 55.4 \\
$\mathrm{C}(34)$ & $12: 00: 02$ & 379.0 \\
\hline \multicolumn{4}{c}{$\langle$ within $95 \%$ confidence range } \\
$\mathrm{C}+\mathrm{B}$ & $11: 50: 03-11: 50: 25$ & 140.3 \\
\hline
\end{tabular}

Two workers had left the Setagaya tunnel before 11:30 a.m. on the day of the fire. They left two gasoline torches in the tunnel so as to continue the maintenance work after having lunch. One of them had just returned to the Setagaya telephone station, when he was informed that black smoke was coming from the tunnel. There were several witness who saw smoke first appearing from the man-hole and vents around 11:30 - 
11:35 a.m.. The start time of the Setagaya cable fire was estimated from the times reported by those witnesses and workers around 11:30, and which coincides with the time estimated from the fire data in the experiment.

Table 5 Flapsed time from cables $\# 9+\# 10$ to cable $\# 34$

\begin{tabular}{cl}
$\operatorname{Exp} \cdot 1$ & $1 \min 25 \mathrm{sec}$ \\
$\operatorname{Exp} \cdot 2$ & $2 \min 31 \mathrm{sec}$ \\
Real fire & $7 \min 50 \mathrm{sec}-11 \min 46 \mathrm{sec}$ \\
\hline
\end{tabular}

\section{Model}

\section{Experiment}
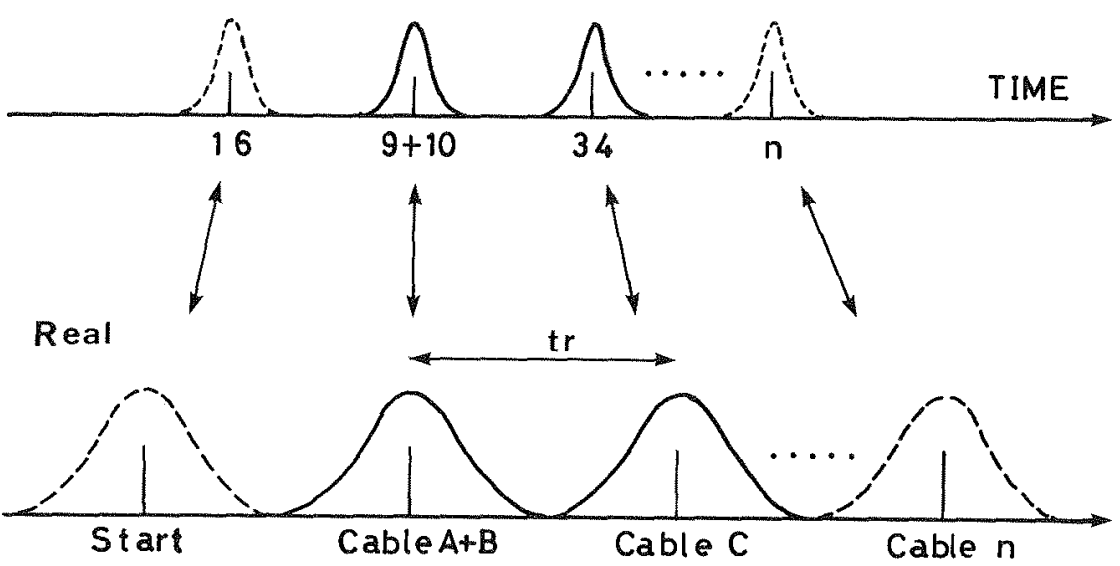

Figure 5 Model of the fire propagation in the experiment and the Setagaya fire based on the normal distribution of stoppage.

\section{CONCLUSION}

The sequence of cable function stoppages showed normal distribution against time as observed both in the real fire and the model. Therefore, we could estimate the development of the real fire based on the results of the experimental fire.

When telephone cables without fire retardant sheathing are set on fire, they lose commication function within 5 - 6 min. Extremely fast development of thick smoke must be expected. Experimental results indicated that the development of the burning front in a tunnel can be as fast as $3 \mathrm{~m} / \mathrm{min}$. Effective fire fighting measures against a tunnel fire are difficult to apply, because, smoke severely limits visibility after only 3 - 5 min and there are few access holes. Smothering with an inertgas, such as nitrogen and/or exhaust gas, is one of possible method of extinguishing a cable tunnel fire. 
In the case of the Setagaya Cable Fire, the fire spread into the Station was stopped by class A fire resisting door(s). This helped the earlier restoration of communication function of the telephone network compared to the fire which had occurred in New York City [12]. This suggests that compartmentation of such tunnels by fire resisting doors is one effective method against fire development. It is also exceedingly important to give some fire retardation to the telephone cable sheathing as well as to have an early fire detecting system, particularly in a long tunnel.

\section{ACKNOWLEDGMENT}

Professor Takashi HANDA was the Head of the committee which made the basic plan for this series of experiments. Unfortunately he had cancer and passed away. We deeply miss him. The authors wish to thank to Professor Kunio Kawagoe and Dr. Tomoyuki Mizuno for their kind advice and help in carrying out those experiments, and we also want to thank Mr. Susumu Matsunobu for his help in data processing.

\section{RETERENCES}

1) For example;"Kindai-Shoubou (Firemen)" p14-59, Feb., 1985 (written in Japanese) published by Zenkoku kajo Horei Shuppan Co., Ltd.

2) National Fire Protection Association, 1984 National Electrical Code, Section 800-3(d)

3) Underwriters Laboratories, UL 910 Standard for Test Method for Fire and Smoke Characteristics of Cable Used in Air-Handling Spaces

4) Beyreis, J.R., Skjordahl,J.W., Kaufmann, S., and Yocum, M.M.; Proc. Twenty-fifth Intr. Wire and Cable Symp. p291-295 (1976)

5) Przybyla, K.J., Guida, T.J., Williams, J.L., and Kaufmann, S., ; Journal of Fire Science vol.3 p9-25 (1985)

6) Kaufmann, S., Fire Journal Vol.79 No.6 p33-38 (1985)

7) Hayashi, F., Watanabe, T., and Handa, T., The 8th Joint Panel Meeting UJNR Panel on Fire Research and Safety, May (1985)

8) Hayashi, F., Watanabe, T., Jour. of Fire Science and Technology vol.5, No.2 p129-140 (1985)

9) Suzuki, H., and Hane,Y., "KASAI", Bull. of Japan Assoc. Fire Science and Engineering Vol. 28, No.4, p22-30 (1978)

10) Suzuki, H., Hane, Y., Hayashi, T., and Kubota, S.,; THE FURUKAWA ELECTRIC REVIEW, No.62 p55-66, DEC. (1977) (written in Japanese)

11) Yanai, E., "KASAI" Bull. of Jpn Assoc. Fire Science and Engineering Vol.35 No.5 p33-39 (1985) (written in Japanese)

12) Rodriguez. et al., W.N.Y.F. 3rd, 4 (1976) 